\title{
El enfoque de derechos humanos en las intervencio- nes de agua
}

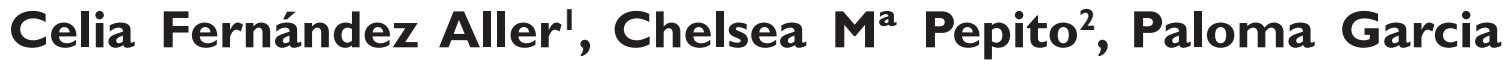 Moreno $^{3}$}

Resumen: El enfoque de Derechos humanos no ha sido suficientemente sistematizado mediante experiencias exitosas. Este artículo pretende contribuir a la difusión de procesos de aplicación del enfoque en intervenciones de desarrollo. Aunque Nicaragua es un Estado parte de las convenciones internacionales que establecen el derecho al agua, éste está siendo vulnerado en muchas de sus categorías y principios. Para el estudio de la situación real del país se ha investigado y analizado el marco normativo a todos los niveles. Además, se han desarrollado herramientas e instrumentos para poder realizar el seguimiento de la realización progresiva del derecho.

Palabras clave: Agua, Derecho humano, enfoque de derechos humanos, saneamiento.

Fecha de recepción: 19 de marzo de 2015.

Fecha de admisión: 19 de mayo de 2016.

\footnotetext{
1 Universidad Politécnica de Madrid, ETSISI. cfaller@evi.upm.es

${ }^{2}$ Estudiante de Máster en Tecnología para el Desarrollo Humano UPM. chelseapees@gmail.com

${ }^{3}$ ONGAWA. paloma.garcia@ongawa.org
} 


\section{The European Union and immigration}

Abstract: Human Rights approach has not been systematized through successful experiences and, although Nicaragua has signed the international conventions about the Right of Water and Sanitation Access, it is being violated in lots of its dimensions. The legislative framework has been analyzed, as well as the tools to monitor the progressive realization of this Right.

Key-words: Water, Human Right, human rights based approach, sanitation.

\section{L'approche des droits humains dans les interventions de l'eau}

Résumé: L'approche des droits humains si a pas été suffisamment systématisé par le biais d'expériences réussies. Cet article vise à contribuer à la diffusion des processus de demande sur les interventions de développement. Bien que le Nicaragua est un État qui fait partie aux conventions internationales qui établissent le droit à l'eau, celvi-ci est violé dans plusieurs de ses catégories et principes. Pour étudier la situation réelle dans le pays a analysé le cadre réglementaire à tous les niveaux. En outre, nous avons mis au point des outils et des instruments pour pouvoir suivre la réalisation progressive du droit.

Mots clé: Eau, Droits de l'Homme, approche des droits humains, assainissement.

\section{Introducción}

Mucho se ha escrito sobre qué es el enfoque de derechos humanos, pero poco se han sistematizado las experiencias que expliquen cómo hacerlo, y cuáles son las claves del éxito de las intervenciones bajo este marco de actuación.

En este trabajo se parte de la actividad desarrollada por ONGAWA Ingeniería para el Desarrollo Humano, que es una Organización No Gubernamental (ONG) de Desarrollo que tiene como misión poner la tecnología al servicio del desarrollo humano para construir una sociedad más justa y solidaria. ONGAWA tiene una trayectoria de trabajo llevada a cabo conjuntamente con La Cuculmeca, una organización nicaragüense, y el apoyo técnico de la Universidad Carlos III de Madrid, la Universidad Politécnica de Madrid y la Universidad Politécnica de Cataluña.

El trabajo relacionado con el derecho humano al agua y al saneamiento (DHAS) en Nicaragua se remonta, para ONGAWA, al año 2008. Varias son sus líneas de trabajo: a) trabajo de dotación de infraestructuras y apoyo a la gestión de los recursos hídricos; b) capacitación en torno al concepto de DHAS; c) elaboración 
de informes sobre el estado del DHAS; d) trabajo de incidencia en Naciones Unidas, a través de la participación en el Examen Periódico Universal; e) apoyo en la elaboración de manuales metodológicos que ayuden a incorporar el enfoque de derechos humanos.

En 2008 realizó el primer informe sobre la situación del DHAS en Nicaragua ${ }^{4}$. Unos años más tarde, en 2012, se comenzó la tarea de elaborar el $2^{\circ}$ informe sobre DHAS, ampliando la muestra hasta hacerla representativa, abarcando todos los departamentos del país, e incluyendo la participación de los municipios.

El territorio sobre el que se actúa, Nicaragua, es un país con cerca de 130.000 $\mathrm{km}^{2}$ y unos 6.000.000 habitantes. Una buena parte de la población se concentra en el campo, aunque eso ha venido cambiando en el último tiempo por la falta de oportunidades y la enorme migración hacia las ciudades y hacia otros países, como Costa Rica. La mayor parte (56\%) se concentra en la Región Pacífico, 31\% en la Región Central Norte y el restante 13\% en la Región Atlántica, que abarca la mayor parte del territorio nacional.

Nicaragua es uno de los países más pobres de América Latina; su PIB per cápita es solo un tercio del promedio regional. Su nivel de pobreza extrema alcanza al $45,5 \%$ de la población -menos de 1 \$ diario-, y un nivel de pobreza del 79,9\% de su población -menos de $2 \$$ diarios-. La riqueza está repartida de manera muy desigual ya que el $20 \%$ de la población más rica acapara el $47 \%$ del consumo nacional y el $20 \%$ más pobre, el $6 \%$. Es el país de Centroamérica con menor producto interior bruto, y con el menor crecimiento económico.

Sus recursos hídricos están distribuidos de manera irregular por todo el territorio, sin una relación directa con las demandas de agua. El $79 \%$ de la población nicaragüense tiene acceso al agua potable, aunque este porcentaje difiere en las zonas urbanas (90\%), frente a las rurales (63\%). En cuanto al saneamiento, la cobertura a nivel nacional es del $47 \%$, siendo también diferente en las zonas urbanas (56\%), que en las rurales (34\%). Esta desigualdad según el ámbito rural y urbano es significativa teniendo en cuenta que el porcentaje de población que vive en zonas rurales es menor al $44 \%$.

${ }^{4}$ Disponible en http://www.simas.org.ni/publicacion/5244/informe-sobre-el-derecho-humanode-acceso-al-agua-potable-y-saneamiento-en-nicaragua 
Gráfico I. Datos oficiales sobre acceso al agua y al saneamiento en Nicaragua Centroamérica:Acceso a Agua Potable y Saneamiento Años 1990-2004 (Porcentaje de población)

\begin{tabular}{|l|c|c|c|c|}
\cline { 2 - 5 } \multicolumn{1}{c|}{} & \multicolumn{2}{c|}{ Saneamiento } & \multicolumn{2}{c|}{ Agua Potable } \\
\cline { 2 - 5 } \multicolumn{1}{c|}{} & $\mathbf{1 9 9 0}$ & $\mathbf{2 0 0 4}$ & $\mathbf{1 9 9 0}$ & $\mathbf{2 0 0 4}$ \\
\hline Costa Rica & - & 92 & - & 97 \\
\hline El Salvador & 51 & 62 & 67 & 84 \\
\hline Guatemala & 58 & 86 & 79 & 95 \\
\hline Honduras & 50 & 69 & 84 & 87 \\
\hline Nicaragua & 45 & 47 & 70 & 79 \\
\hline Panamá & 71 & 73 & 90 & 90 \\
\hline
\end{tabular}

Fuente: PNUD, Informe Desarrollo Humano 2006.

Nicaragua: abastecimiento de agua (\%)

\begin{tabular}{|l|c|c|c|c|c|c|}
\hline \multirow{2}{*}{$\begin{array}{c}\text { Abastecimiento } \\
\text { de agua }\end{array}$} & \multicolumn{2}{|c|}{ Total } & \multicolumn{2}{c|}{ Urbano } & \multicolumn{2}{c|}{ Rural } \\
\cline { 2 - 7 }$\%$ & Viviendas & Población & Viviendas & Población & Viviendas & Población \\
\hline $\begin{array}{l}\text { Tubería dentro de } \\
\text { la vivienda }\end{array}$ & 100 & 100 & 100 & 100 & 100 & 100 \\
\hline $\begin{array}{l}\text { Tubería fuera de } \\
\text { la vivienda pero } \\
\text { dentro del terreno }\end{array}$ & 20.3 & 39.6 & 62.8 & 62.7 & 10.7 & 10.4 \\
\hline Puesto público & 3.2 & 3.2 & 1.5 & 1.5 & 5.4 & 5.4 \\
\hline Pozo & 16.4 & 16.7 & 5.4 & 5.6 & 31.1 & 30.8 \\
\hline Privado & 10.8 & 11 & 4 & 4.2 & 19.9 & 19.7 \\
\hline Público & 5.6 & 5.7 & 1.4 & 1.4 & 11.2 & 11.1 \\
\hline $\begin{array}{l}\text { Río, manantial o } \\
\text { quebrada }\end{array}$ & 12 & 13.2 & 0.5 & 0.5 & 27.3 & 29.3 \\
\hline Otra forma & 7 & 6.2 & 5.6 & 5 & 8.8 & 7.8 \\
\hline Ignorado & 0.7 & 0.5 & 0,8 & 0.6 & 0.5 & 0.3 \\
\hline
\end{tabular}

Fuente: Censo Nacional 2005. 
Existen datos muy diversos sobre el porcentaje de población con acceso al agua potable y saneamiento en Nicaragua. Según la Asociación de municipalidades, al menos en 55 municipios de los 153 del país, en los que habita la quinta parte de la población, la mayoría de la gente no tiene acceso al agua potable.

Por otra parte, el sector rural es el más afectado pues el acceso al agua potable no supera el 48\%, según datos de la Organización Panamericana de la Salud (OPS).

Otros datos señalan que un tercio de la población del país tiene agua para beber dentro de la vivienda y otra tercera parte lo tiene fuera. Como es de esperarse en un país con importantes niveles de desigualdad, este porcentaje se distribuye desigualmente entre los departamentos del país y por condición socio-económica de la población.

Por otro lado, el hecho de contar con redes de servicios de agua no asegura la existencia de un abastecimiento de agua continuo debido principalmente al agotamiento que han venido sufriendo las principales fuentes de agua por el deterioro del medio ambiente y el crecimiento poblacional.

El tema de la calidad del agua es generalmente poco abordado en las estadísticas nacionales; sin embargo, el Ministerio de Salud sostiene que no todos los sistemas de abastecimiento de agua cuentan con los medios necesarios para tratar el agua de fuentes diversas, muchas veces contaminadas por aguas residuales.

La problemática del agua repercute de manera directa en la situación de salud de la población. De acuerdo a diversas estimaciones, cerca del $80 \%$ de los problemas de salud que motivan consultas en el sistema público está vinculada con el agua, como las diarreas, conjuntivitis y problema de la piel, entre otros.

La falta de acceso en el hogar aumenta la carga laboral fundamentalmente de las mujeres, que son las encargadas de mayor parte de las tareas domésticas, especialmente de las más pobres y de las que viven en las zonas rurales. Esta tarea requiere con frecuencia de varias horas de camino cargando el agua desde la fuente hasta el hogar. Muchas veces, son apoyadas por los niños y niñas mayores.

A esta situación se le suma el deterioro ambiental y las modificaciones climatológicas que en los últimos años han cambiado el caudal de los ríos que abastecen de agua, disminuyéndolos y, aumentando los niveles de contaminación con agroquímicos y salinización por el vertido de aguas residuales industriales y domésticas sin tratamiento alguno. Aunque el agua y saneamiento ya se considera por parte de 
todo el sistema de las Naciones Unidas un derecho humano, es un derecho que no se garantiza ni se respeta en Nicaragua.

A pesar de que Nicaragua es Estado Parte en las Convenciones que establecen el derecho al agua, este derecho está siendo vulnerado para gran parte de la población, fundamentalmente la población de zonas rurales, asentamientos urbanos y núcleos más vulnerables.

La cobertura de agua y saneamiento es de forma irregular por todo el territorio, sin existir una correspondencia con las demandas de agua. Existe asimismo una gran diferencia entre el ámbito urbano y el rural, en cuanto al disfrute de este derecho.

En la zona de mayor densidad poblacional es frecuente que las ciudades no cuenten con sistemas de recolección y tratamiento de aguas residuales, de manera que se vierten directamente en las masas de agua superficiales, comprometiendo su calidad.

\section{Líneas de la intervención con enfoque de derechos humanos}

En este trabajo se explicarán las principales conclusiones derivadas de la ejecución de un proyecto desarrollado conjuntamente por ONGAWA junto con otras organizaciones, el cual ha consistido en una investigación aplicada que busca facilitar instrumentos de análisis e incidencia que promuevan y mejoren el acceso al derecho al agua y saneamiento desde el enfoque de derechos.

Este proyecto se ha ejecutado como parte de un proceso muy largo de defensa del Derecho Humano al Agua y al Saneamiento que se remonta al año 2008 y que seguirá adelante una vez finalizada la financiación recibida. Ello es posible gracias a que los actores involucrados tienen una trayectoria de trabajo conjunto y comparten la convicción de que el enfoque de derechos es el idóneo para las intervenciones relacionadas con agua y saneamiento, pese a estar tradicionalmente el foco localizado en la provisión de servicios.

Con este proyecto de investigación se ha intentado contribuir en el proceso de consecución de los Derechos Humanos. Las líneas de trabajo que se han seguido son las de un análisis riguroso de los marcos normativos nacional, regional e internacional que hacen referencia al DHAS y se han tratado de localizar los elementos del mismo (tal y como reconoce la Observación General $n^{\circ} 15$ del Comité de Derechos Económicos, Sociales y Culturales) y los principios de derechos humanos. 
Aprovechando el análisis se ha realizado un mapeo de los actores con competencias en agua y saneamiento en Nicaragua; una investigación acerca de las herramientas e instrumentos que existen en el marco de las Naciones Unidas (NNUU) y en otros espacios regionales e internacionales de incidencia que permitan canalizar las inquietudes, debilidades, incumplimientos relacionados con el DHAS.

Se ha generado un documento de síntesis sobre el marco normativo nacional e internacional del derecho al agua a todos los niveles propuestos, así como otro sobre los actores con responsabilidad en las tareas de respetar, proteger y realizar el derecho mediante un análisis marco de actores en relación al derecho al agua y al saneamiento en Nicaragua. Se han revisado los instrumentos elaborados para incorporar las dimensiones y categorías del derecho mediante la inclusión de éstos en las encuestas realizadas, así como el análisis de las categorías del derecho y de los principios.

Gráfico 2.Criterios del derecho humano al agua:categorías del derecho humano al agua incorporadas en la normativa relativa al derecho al agua y al saneamiento

\begin{tabular}{|l|l|}
\hline $\begin{array}{l}\text { Disponibilidad. } \\
\text { Agua en cantidad } \\
\text { aceptable, } \\
\text { y servicio } \\
\text { continuado. }\end{array}$ & $\begin{array}{l}\text { Ley General de Aguas Nacionales, Artículo 71.- En los casos en } \\
\text { donde no exista cobertura permanente y continua del sistema de } \\
\text { acueducto para abastecimiento de agua potable, las instituciones } \\
\text { competentes y responsables de este servicio público, deberán ga- } \\
\text { rantizar temporalmente el abastecimiento mínimo en cantidad y } \\
\text { calidad, por cualquier forma y medios. }\end{array}$ \\
\hline $\begin{array}{l}\text { Calidad. Agua } \\
\text { potable, salubre. }\end{array}$ & $\begin{array}{l}\text { Ley General de Salud, 2002. Artículo 69.- El Saneamiento am- } \\
\text { biental comprende la promoción, educación, mejora, control y } \\
\text { manejo del ruido, calidad de aguas, eliminación y tratamiento } \\
\text { de líquidos y sólidos, aire [...] El Ministerio de Salud en el ámbito } \\
\text { de su competencia tendrá la facultad de determinar los rangos } \\
\text { máximos contaminantes permisibles y las normas técnicas a que } \\
\text { deben sujetarse las personas naturales o jurídicas en las materias } \\
\text { relacionadas con el medio ambiente. } \\
\text { Reglamento de la LEY 620 /Decreto 106-2007. Artículo 4.- Nor- } \\
\text { mativas de Calidad. ElMinisteriode Salud (MINSA) en coordinación } \\
\text { con el INAA, Ministerio del Ambiente y los Recursos Naturales } \\
\text { (MARENA) y MAGFOR, elaborará las normas técnicas de calidad } \\
\text { del agua para consumo humano, tomando en consideración los } \\
\text { contaminantes orgánicos persistentes (COP), prohibidos en Nica- } \\
\text { ragua, así como cualquier otro tipo de contaminante tóxico para } \\
\text { el consumo humano. }\end{array}$ \\
\hline
\end{tabular}




\begin{tabular}{|c|c|}
\hline $\begin{array}{l}\text { Aceptabilidad } \\
\text { cultural. }\end{array}$ & $\begin{array}{l}\text { Los CAPS se regirán por los siguientes principios: } \\
\text { d.- Pluralidad, reconocimiento de la diversidad de valores, opi- } \\
\text { niones y prácticas de vivencia comunitaria, incluyendo el respeto } \\
\text { a las mismas por parte de las autoridades locales, regionales y } \\
\text { nacionales en la autogestión comunitaria del agua. }\end{array}$ \\
\hline $\begin{array}{l}\text { Accesibilidad } \\
\text { geográfica. } \\
\text { Seguridad física. }\end{array}$ & $\begin{array}{l}\text { Reglamento de la LEY } 620 \text { /Decreto 106-2007Artículo 9.- Prio- } \\
\text { ridades. Necesariamente en las políticas y demás instrumentos de } \\
\text { gestión del agua deberá priorizarse el acceso continuo, de calidad, } \\
\text { y a precios accesibles, a aquellos sectores urbanos y rurales que } \\
\text { nunca han gozado de este derecho humano básico. Una parte } \\
\text { razonable de los recursos que se integren al Fondo Nacional del } \\
\text { Agua, deberá ser destinada a mejorar, o crear redes de agua } \\
\text { potable, y de saneamiento a estos sectores. } \\
\text { Artículo 5.- [...]Tampoco podrán interrumpirse estos servicios a } \\
\text { hospitales, centros de salud, escuelas, orfelinatos, asilos para } \\
\text { ancianos, centros penitenciarios, estaciones de bomberos y } \\
\text { mercados populares. }\end{array}$ \\
\hline $\begin{array}{l}\text { Asequibilidad } \\
\text { económica: precio } \\
\text { del agua/tarifas. }\end{array}$ & $\begin{array}{l}\text { Ley General de Aguas, Artículo 5.- Es obligación y prioridad in- } \\
\text { declinable del Estado promover, facilitar y regular adecuadamente } \\
\text { el suministro de agua potable en cantidad y calidad al pueblo } \\
\text { nicaragüense, a costos diferenciados y favoreciendo a los sectores } \\
\text { con menos recursos económicos. La prestación de este servicio vital } \\
\text { a los consumidores en estado evidente de pobreza extrema no } \\
\text { podrá ser interrumpida, salvo fuerza mayor, debiendo en todo } \\
\text { caso proporcionárseles alternativas de abastecimiento temporal, } \\
\text { sean en puntos fijos o ambulatorios. } \\
\text { Ley General de Aguas, Artículo } 71 \text { - Las instituciones competentes } \\
\text { y responsables de este servicio público, [...] elaborarán los pro- } \\
\text { yectos básicos para el abastecimiento de agua potable a costos } \\
\text { realmente accesibles, primordialmente cuando sea destinada } \\
\text { a sectores marginales o a población ubicada en asentamientos } \\
\text { precaristas urbanos o rurales. }\end{array}$ \\
\hline $\begin{array}{l}\text { Igualdad y no } \\
\text { discriminación } \\
\text { (enfoque de } \\
\text { género, inclusión } \\
\text { grupos más } \\
\text { vulnerables). }\end{array}$ & $\begin{array}{l}\text { Ley General de Aguas,Artículo 13.- El agua es un recurso vital, } \\
\text { limitado, vulnerable y finito cuya preservación y sustentabilidad } \\
\text { es tarea fundamental e indeclinable del Estado y de la sociedad } \\
\text { en su conjunto. Su acceso es un derecho irrenunciable de todo } \\
\text { ser humano. } \\
\text { Ley General de Aguas, Artículo 6.- La presente Ley reconoce el } \\
\text { derecho de los Pueblos Indígenas de todo el territorio nacional y } \\
\text { el de las Comunidades Étnicas de la Costa Atlántica, para el uso } \\
\text { y disfrute de las aguas que se encuentran dentro de sus tierras } \\
\text { comunales de conformidad a las leyes vigentes que las regulan. }\end{array}$ \\
\hline
\end{tabular}




\begin{tabular}{|c|c|}
\hline $\begin{array}{l}\text { Participación y } \\
\text { empoderamiento. } \\
\text { Acceso a la } \\
\text { información. }\end{array}$ & $\begin{array}{l}\text { Ley General de Aguas, Artículo 13.- [...]f) Participación Ciudada- } \\
\text { na. El Estado debe asegurar la participación de todos los grupos } \\
\text { e interesados, en la formulación e implementación de la política } \\
\text { nacional hídrica y de los planes y programas correspondientes, a } \\
\text { través de procesos que ubiquen las decisiones tan cerca como sea } \\
\text { posible de los directamente afectados por las mismas; } \\
\text { Reglamento de la LEY 620, Decreto 106-2007. } \\
\text { Artículo 6.- Normativas Complementarias. Cualquier normativa } \\
\text { complementaria al presente Reglamento o a los Reglamentos Es- } \\
\text { peciales de esta Ley, será hecha por los organismos competentes } \\
\text { tomando en consideración las opiniones y necesidades de los } \\
\text { pobladores en el sitio donde deba realizarse la actividad vinculada } \\
\text { con el recurso agua, o a través de consultas ciudadanas, cuando } \\
\text { se trata de decisiones administrativas que afecten a la población } \\
\text { en general. } \\
\text { Artículo } 41 \text { - De los Comités de Cuenca. Los Organismos de } \\
\text { Cuenca promoverán e impulsarán la constitución de los Comités de } \\
\text { Cuenca, o bien los interesados en uso de sus derechos de partici- } \\
\text { pación ciudadana, cumpliendo los requisitos establecidos en la Ley, } \\
\text { podrán proponer su formación, presentado para ello su solicitud } \\
\text { de reconocimiento y aprobación ante la Autoridad de Cuenca. } \\
\text { Artículo 75.- Comités de Agua. En las comunidades rurales donde } \\
\text { el prestador de los servicios no tiene cobertura, los sistemas serán } \\
\text { administrados por la comunidad, conformando para ello los Comités } \\
\text { de Agua Potable, que garantizarán el servicio a la comunidad, todo } \\
\text { bajo la supervisión y control de ENACAL. }\end{array}$ \\
\hline $\begin{array}{l}\text { Transparencia y } \\
\text { rendición de cuen- } \\
\text { tas. Sostenibilidad } \\
\text { para las genera- } \\
\text { ciones futuras. }\end{array}$ & $\begin{array}{l}\text { Ley de CAPS 722.- Los CAPS se definen como organizaciones sin } \\
\text { fines de lucro, que de manera voluntaria y electos democráticamente, } \\
\text { tienen a su cargo la administración, operación y mantenimiento } \\
\text { del servicio de agua potable y saneamiento en la comunidad, con } \\
\text { el apoyo de todos los usuarios, a quienes además, rinden cuentas } \\
\text { de sus gestiones y actividades. }\end{array}$ \\
\hline
\end{tabular}

Se ha realizado también una contribución al seguimiento de la realización progresiva de DHAS. Este trabajo se ha centrado en la realización de encuestas a varios niveles (hogares, Comités de Agua Potable y Saneamiento - CAPS, y municipios), en el marco de una encuesta con base en muestra representativa. Actualmente, nos encontramos en fase de análisis de los resultados, que se dirigen a la obtención de un segundo informe de situación del Derecho Humano al Agua y al Saneamiento en Nicaragua. 
En el año 2013 se procedió al levantamiento de encuestas para conocer con más detalle la situación del derecho al agua y al saneamiento en Nicaragua. El objetivo era conocer el estado sobre el cumplimiento del derecho básico sobre la base de la Meta del Milenio No 10, derivada del ODM No 7 y de los instrumentos nacionales e internacionales que contemplan el cumplimiento del Estado de la República de Nicaragua, en el acceso al agua potable y saneamiento con énfasis en el sector rural, a partir de las categorías del derecho humano al agua: Disponibilidad, Calidad, Accesibilidad, Asequibilidad, No Discriminación y Equidad, Derecho a la Participación y la Información.

El primer paso fue el diseño conjunto de los tres tipos de encuestas realizados (Hogares, Comités de Agua Potable y Municipios). El equipo investigador veló por la inclusión de la metodología del enfoque de derechos humanos en el diseño de los instrumentos de campo para la recogida de información con el objetivo de asegurar la incorporación del enfoque de derechos humanos en los criterios básicos de análisis de la situación de acceso de la población al agua y al saneamiento en Nicaragua; además, llevo a cabo un análisis y revisión de los bloques de preguntas a realizar entre las poblaciones encuestadas, los comités de gestión de agua (CAPS), y el personal técnico de los Ayuntamientos. Así mismo, llevó a cabo una verificación de la incorporación de preguntas adecuadas destinadas a evaluar la situación de acceso al agua potable y al saneamiento según los criterios aprobados por Naciones Unidas, en cuanto a cantidad mínima necesaria para consumo doméstico y para obtención de alimentos, en cuanto a calidad del agua, y en cuanto a accesibilidad geográfica, asequibilidad económica y aceptabilidad cultural de los servicios disponibles en el acceso a agua potable y saneamiento.

En este segundo proceso, que ha sido acompañado con la investigación aplicada del proyecto financiado en la convocatoria abierta y permanente de la AECID, se ha podido mejorar el planteamiento del primer informe. En este sentido se han levantado 2400 encuestas correspondientes a 200 comunidades y 20 municipios del país, distribuidos de manera aleatoria.

Una vez revisadas y ajustadas las encuestas a utilizar se capacitó a los equipos locales que iban a hacer las encuestas en las comunidades. Paralelamente se elaboró una guía de observaciones que facilitara la aplicación de las mismas.

El proceso de levantamiento de encuestas en Nicaragua se finalizó en el mes de julio 2013. Se hizo un taller con los participantes, para que todos tuvieran conocimiento de la encuesta y sus objetivos, y posteriormente se distribuyó a la gente en los distintos territorios. A cada comunidad han ido dos encuestadores. 
Es importante tener en cuenta que para la organización de todo el proceso de levantamiento de encuestas como para su posterior análisis ha sido muy importante el trabajo en red que se ha llevado a cabo, así como la colaboración de distintas entidades tanto en el Norte, como en el Sur. El trabajo desarrollado en el marco de este proyecto ha sido recogido como una "buena práctica" en el Toolkit para la realización del derecho humano al agua y al saneamiento de Waterlex 5 .

Otra de las líneas de trabajo ha sido el estudio sobre las metodologías más apropiadas para trabajar el Enfoque Basado en Derechos Humanos (EBDH) y la elaboración de un documento de síntesis y recomendaciones. Para ello se ha hecho el análisis de las metodologías disponibles en el trabajo de agua y saneamiento; se han diseñado propuestas de líneas metodológicas para el agua y saneamiento desde el EBDH y de insumos para la validación de las metodologías propuestas. Para ello se han realizado dos guías metodológicas ${ }^{6}$ para la incorporación del $\mathrm{EBDH}$ en el trabajo de agua y saneamiento.

Además, se ha llevado a cabo un trabajo intenso en el marco del programa a través de la búsqueda de incidencia en los canales de Naciones Unidas ${ }^{7}$.

Entre el 7 y el 9 de mayo, el Consejo de Derechos Humanos realizó el Examen Periódico Universal (EPU) de la República de Nicaragua. El EPU es un mecanismo de dicho Consejo mediante el cual éste vigila regularmente el cumplimiento por cada uno de los 192 Estados miembros de la ONU de sus obligaciones y compromisos en materia de derechos humanos. Para ello tiene en cuenta información recopilada por la Oficina del Alto Comisionado de las Naciones Unidas para los Derechos Humanos y otra información proporcionada por otros interlocutores, entre los que se encuentra la sociedad civil.

Durante estos días, tanto el examen como la atención mediática en Nicaragua se han centrado en los derechos civiles y políticos, los conocidos como de primera generación, girando el debate en torno a la libertad de expresión, el pluralismo de los medios de comunicación, la independencia de los poderes del Estado o la violencia contra las mujeres y la niñez.

\footnotetext{
${ }^{5} \mathrm{http}: / /$ www.waterlex.org/waterlex-toolkit-es/proyecto/la-cuculmeca-nicaragua/

6 Pueden descargarse de: http://www.ongawa.org/wpContent/uploads/2013/09/ DHAguaysaneamiento.pdf

7 DE LUIS ROMERO, E (2013) Incidencia en Naciones Unidas para la defensa del derecho al agua y al saneamiento.
} 
Gráfico 3. Ejemplo de preguntas de la encuesta a hogares realizada en el marco del $2^{\circ}$ informe del DHAS

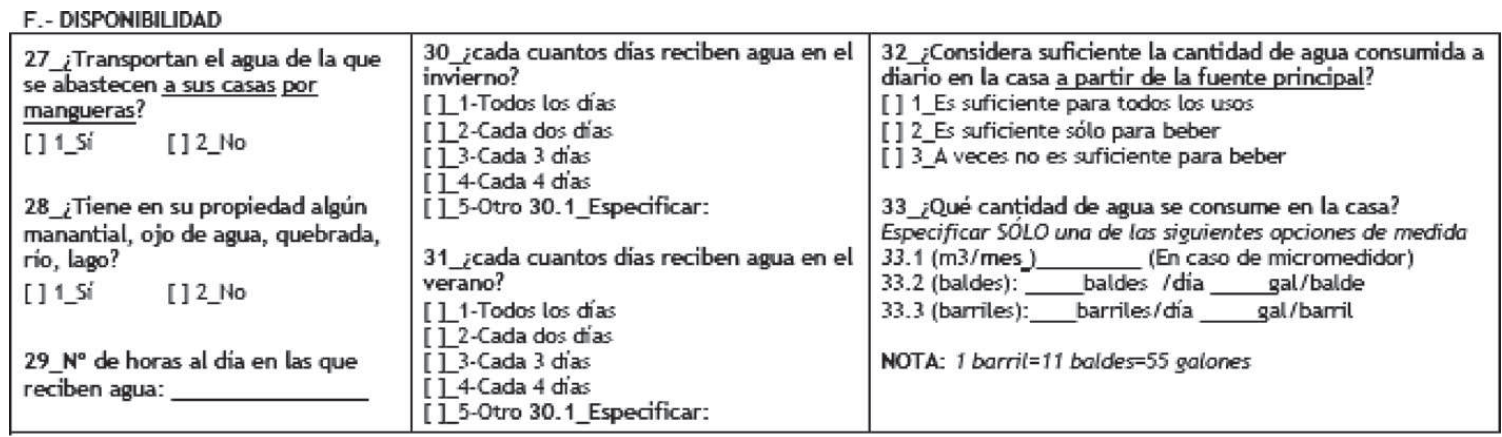

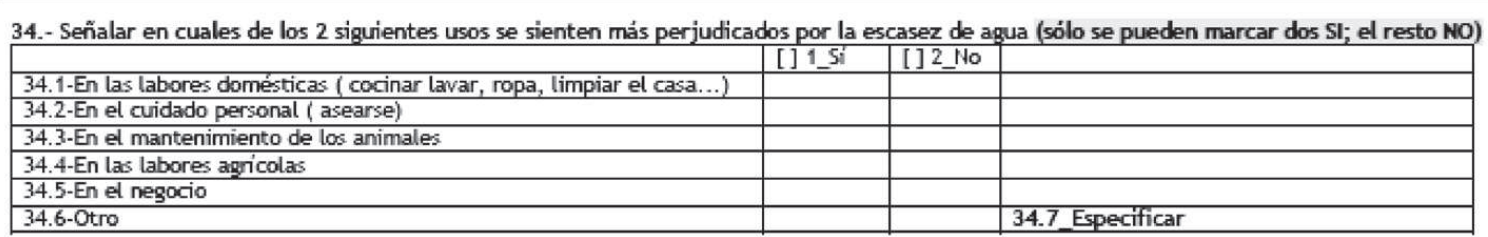

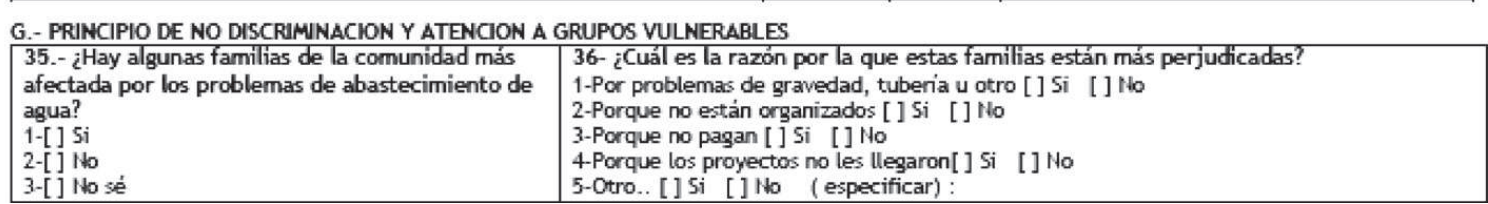

Autores: Óscar Flores Baquero (UPC), Elena de Luis Romero (UPM), Sonia Wheelok (ONGAWA), Cristina Guzmán (UPM), Celia Fernández Aller (UPM), Paloma García (ONGAWA).

Sin duda estos temas tienen gran relevancia y requieren de atención por parte del Estado nicaragüense. No obstante, para una organización de desarrollo como ONGAWA el examen debería haber prestado una mayor atención sobre los derechos de segunda (económicos, sociales y culturales) y de tercera generación (derecho al desarrollo y un medio ambiente sano, por ejemplo), especialmente en lo que respecta al Derecho Humano al Agua. Recordemos que en julio de 2010, a través de la Resolución 64/292, la Asamblea General de las Naciones Unidas reconoció explícitamente los derechos humanos al agua y al saneamiento, reafirmando que un agua potable limpia y el saneamiento son esenciales para la realización de todos los Derechos Humanos.

En este sentido, los datos de Nicaragua muestran que ha habido un considerable avance en este asunto, en línea con lo establecido en la recomendación 54 del EPU 2010 relativa al Derecho Humano al Agua y Saneamiento, aunque es urgente que el Estado vigile la realización progresiva de estos derechos, dando prioridad a la eliminación de discriminaciones que afectan especialmente a las zonas rurales donde la cobertura activa de agua potable es sólo del 33,5\% y la de saneamiento 
del $42,6 \%$, según datos del propio Gobierno recogidos en el Plan Nacional de Desarrollo Humano 2012 - 2016.

Es necesario, por tanto, incrementar los esfuerzos para garantizar la cobertura específica en las zonas rurales, invirtiendo en la sostenibilidad de la gestión comunitaria y municipal del agua y el saneamiento, colaborando desde el Gobierno al reto de la accesibilidad económica para estas poblaciones y apoyando a los Comités de Agua Potable y Saneamiento (CAPS) y a los gobiernos municipales, entidades ambas con gran responsabilidad en la garantía de este Derecho Humano según establece la legislación del país.

El Gobierno de Nicaragua aceptó, ante el Comité DESC de NNUU la recomendación 114.109 que consistió en "Continuar supervisando la garantía del ejercicio del Derecho Humano al Agua Potable y Saneamiento, respetando el principio de no discriminación, prestando atención específica a las comunidades rurales y a los grupos vulnerables y apoyando a los Comités de Agua Potable y Saneamiento así como a los Gobiernos Municipales".

\section{Resultados}

Una vez levantadas las encuestas, se procedió al procesamiento de la información y al análisis de los resultados. Estos arrojaron cifras muy diferentes a las que se manejan en las estadísticas oficiales, que normalmente se centran en acceso, dejando de lado el resto de las categorías y principios del derecho.

Los principales resultados que se pueden extraer del informe son los siguientes:

\section{I. Derecho humano al agua}

\section{I.I. Disponibilidad derecho al agua}

Los primeros datos son los relativos a disponibilidad o abastecimiento de agua para cada persona, de manera suficiente y continua, para usos personales y domésticos, lo que normalmente comprende el consumo, el saneamiento, la colada, la preparación de alimentos y la higiene personal y doméstica (Observación General $n^{\circ} 15$ del Consejo de NNUU). 
Un 30\% de la población encuestada cuenta con un sistema de tubería interno a la vivienda. Si se tienen en cuenta los hogares que disponen de tuberías en el patio o parcela, se obtiene que un $45 \%$ de los encuestados gozan de sistemas de conexión (sistema de tubería y llave).

Gráfico 4. Sistemas de disponibilidad de agua en los hogares entrevistados

\begin{tabular}{|l|r|r|}
\hline Sistema de tuberías y llaves en vivienda propia & 723 & $30 \%$ \\
\hline Sistema de tuberías y llaves en patio propio & 365 & $15 \%$ \\
\hline Sistema de tuberías y llaves en Fuente pública & 53 & $2 \%$ \\
\hline Sistema de tuberías y llaves en vivienda vecino & 53 & $2 \%$ \\
\hline Pozo Perforado & 287 & $12 \%$ \\
\hline Pozo Excavado Protegido & 340 & $14 \%$ \\
\hline Ojo de Agua protegido & 184 & $8 \%$ \\
\hline Captación de agua de lluvia & 3 & $0 \%$ \\
\hline Agua embotellada & 15 & $1 \%$ \\
\hline Pozo Excavado No Protegido & 136 & $6 \%$ \\
\hline Ojo de Agua No protegido & 130 & $5 \%$ \\
\hline Agua superficial & 108 & $5 \%$ \\
\hline No contesta & 1 & $0 \%$ \\
\hline
\end{tabular}

Fuente: elaboración propia.

Otro 38\% tendrían acceso a otros sistemas de agua mejorados (según clasificación del JMP) $)^{8}$, con lo cual obtendrían el agua bien acudiendo a una pileta pública o fuente pública de agua (de un sistema de tuberías, SAP), o a través de un pozo perforado, un pozo excavado protegido o un manantial $v$ ojo de agua protegidos.

Un $12 \%$ tendría acceso a sistemas de agua no mejorados, lo que quiere decir que se abastecen de manantiales $u$ ojos de agua no protegidos, pozos excavados no protegidos o de aguas superficiales. Cabe destacar que el 5\% restante de los hogares encuestados utilizan agua superficial, procedente de ríos, presas, lagos, estanques, arroyos, canales o quebradas como sistema de abastecimiento.

${ }^{8}$ http://www.wssinfo.org/fileadmin/user_upload/resources/JMP_report_2014_webEng.pdf 
Analizando los resultados por regiones, se observa que existe mayor porcentaje de familias que disponen de sistemas de conexión por tuberías en la región de Pacífico (55\%), seguida por la región de Central $(42 \%)$ y por último la región de Caribe (29\%). Respecto al acceso a sistemas de agua no mejorados es mayor en las regiones de Central (14\%) y Caribe (12\%).

Otro de los datos interesantes al hablar de la disponibilidad es la continuidad en el servicio, tanto a nivel de horas al día como según las diferentes estaciones. Del análisis de las encuestas se percibe que un $76 \%$ de las familias entrevistadas consideran que tienen acceso a sistemas mejorados en cualquier época del año, si bien un $24 \%$ no tienen asegurado este acceso en todas las estaciones del año.

La cantidad de agua (litros por persona y por día) consumida en los hogares es preocupante en cierta medida. Como se observa en la gráfica, la mayoría de las familias consumen entre 20 y $50 \mathrm{~L} /$ pd y un porcentaje de familias nada despreciable, menos de $20 \mathrm{~L} / \mathrm{pd}$.

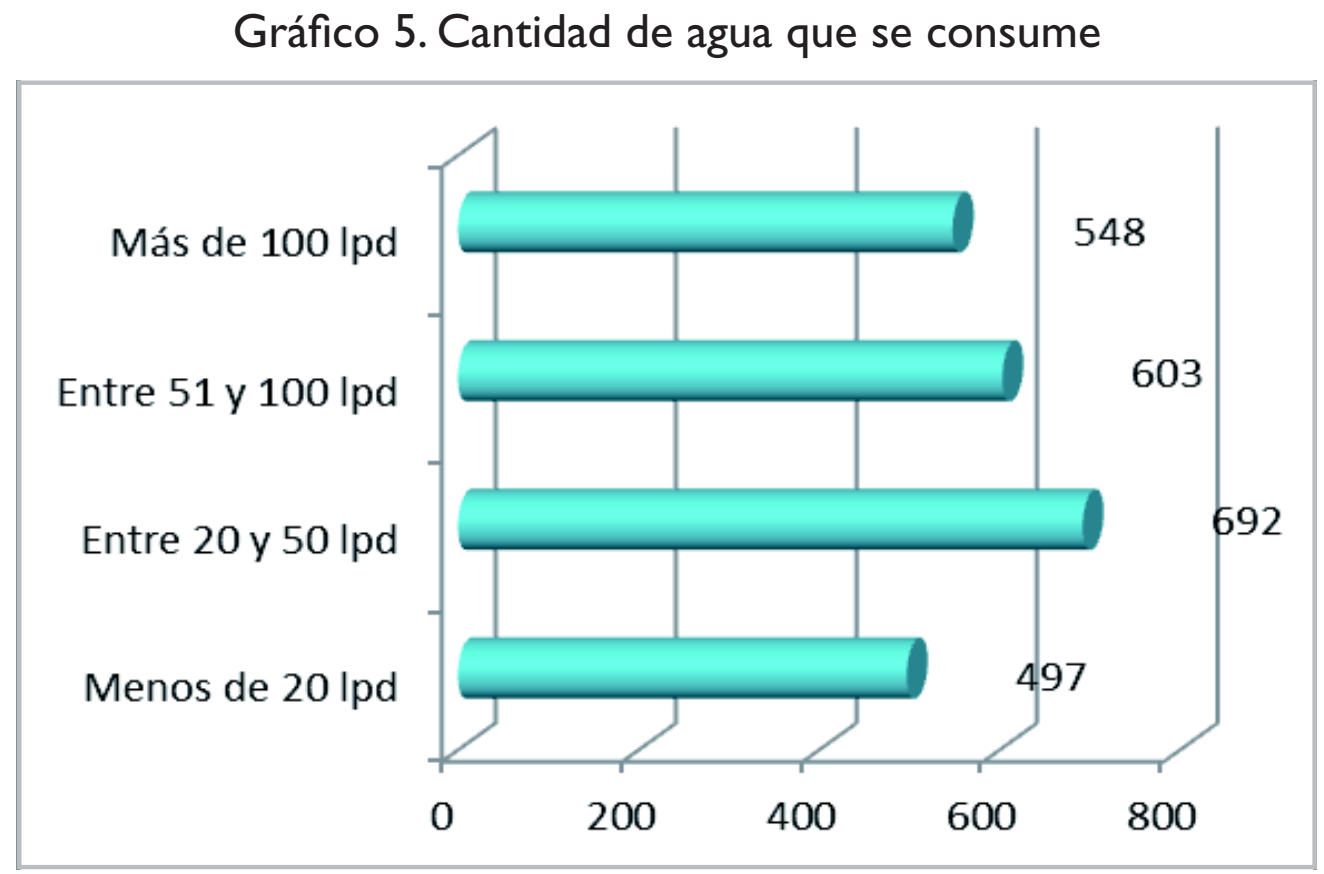

Fuente: elaboración propia.

El resultado de las encuestas a hogares muestra que un $68 \%$ de las familias consideran que tienen acceso a agua para todos los usos. Sin embargo, el $22 \%$ considera que tienen agua suficiente pero solo para beber (lo que implica que tienen que 
buscar otras fuentes para usos como la higiene personal o doméstica y la colada) y el $8 \%$ restante no tiene agua en cantidad suficiente incluso para satisfacer su necesidad básica de agua para consumo.

Gráfico 6. Percepción en torno a la disponibilidad

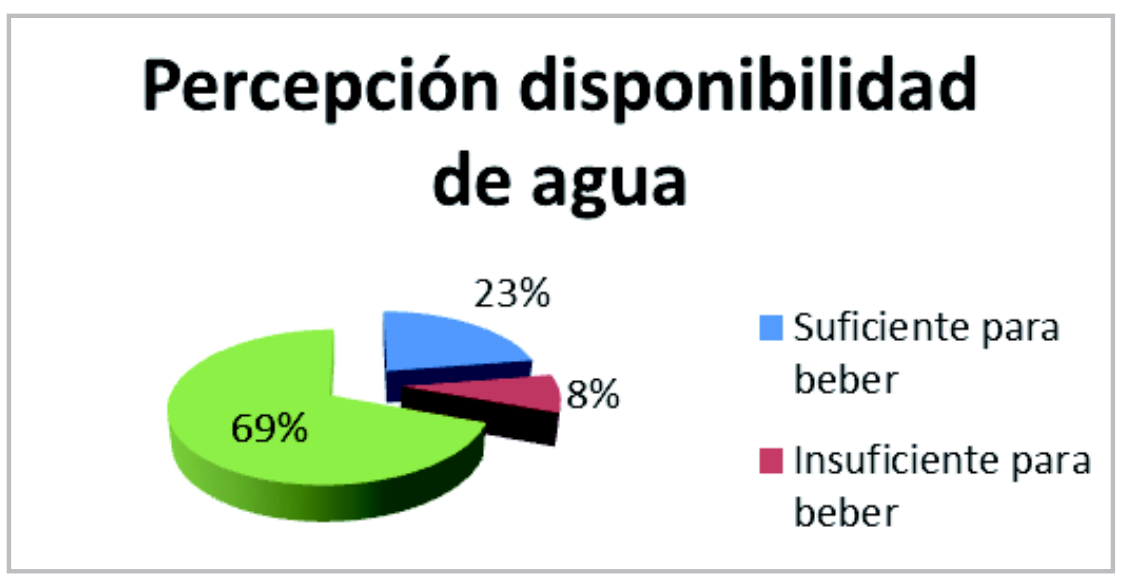

Fuente: elaboración propia.

Desde el punto de vista del derecho, y a la vista de los resultados obtenidos, un $30 \%$ de la población no tiene acceso a agua para satisfacer sus necesidades personales y domésticas que el derecho garantiza, como son el agua para consumo, saneamiento, colada, preparación de alimentos y la higiene personal y doméstica.

Si analizamos los resultados teniendo en cuenta el género de los entrevistados, se observa que las mujeres se ven más afectadas por la escasez de agua en las labores domésticas y en el cuidado personal, mientras que los hombres se ven más perjudicados en el mantenimiento de los animales y en las labores agrícolas. Los resultados de la encuesta de CAPS muestran que un 63\% considera que la cantidad de agua que hay en la comunidad es la adecuada para responder a las necesidades de la población, frente a un $37 \%$ que no lo considera. Por tanto es destacable la alta percepción de que la cantidad de agua que hay en la comunidad no es la adecuada para responder a las necesidades de la población.

\section{I.2.Accesibilidad del derecho al agua}

El agua y las instalaciones y servicios de agua y saneamiento se consideran accesibles cuando están en el interior de cada hogar, institución educativa y lugar de trabajo, o en su cercanía inmediata. La accesibilidad, al facilitar las prácticas 
de higiene, tiende a mejorar las condiciones de vida. Además de la distancia adecuada entre la fuente de agua y el lugar de consumo, la accesibilidad implica también la garantía de la seguridad física para quienes acceden a los servicios de agua. Todos los servicios e instalaciones de agua, deben ser de calidad suficiente y culturalmente adecuados.

Para considerar la dimensión de accesibilidad física, se han tomado en cuenta como indicadores la cercanía al punto de agua y la valoración de las familias de la seguridad en el acceso al punto de agua.

El análisis de los resultados muestra que un elevado número de familias tienen que desplazarse para ir a recoger agua. El siguiente gráfico muestra el tiempo que emplean las familias en la tarea de recogida de agua, considerando como tal la ida a la fuente de agua, la espera en el punto de agua y la vuelta. La mayoría de las familias que tienen que desplazarse a por el agua tardan entre 5 y 30 minutos. Resaltar que un $8 \%$ de las familias que tienen que desplazarse a por el agua tardan más de 30 minutos.

Gráfico 7. Distancia al punto de agua

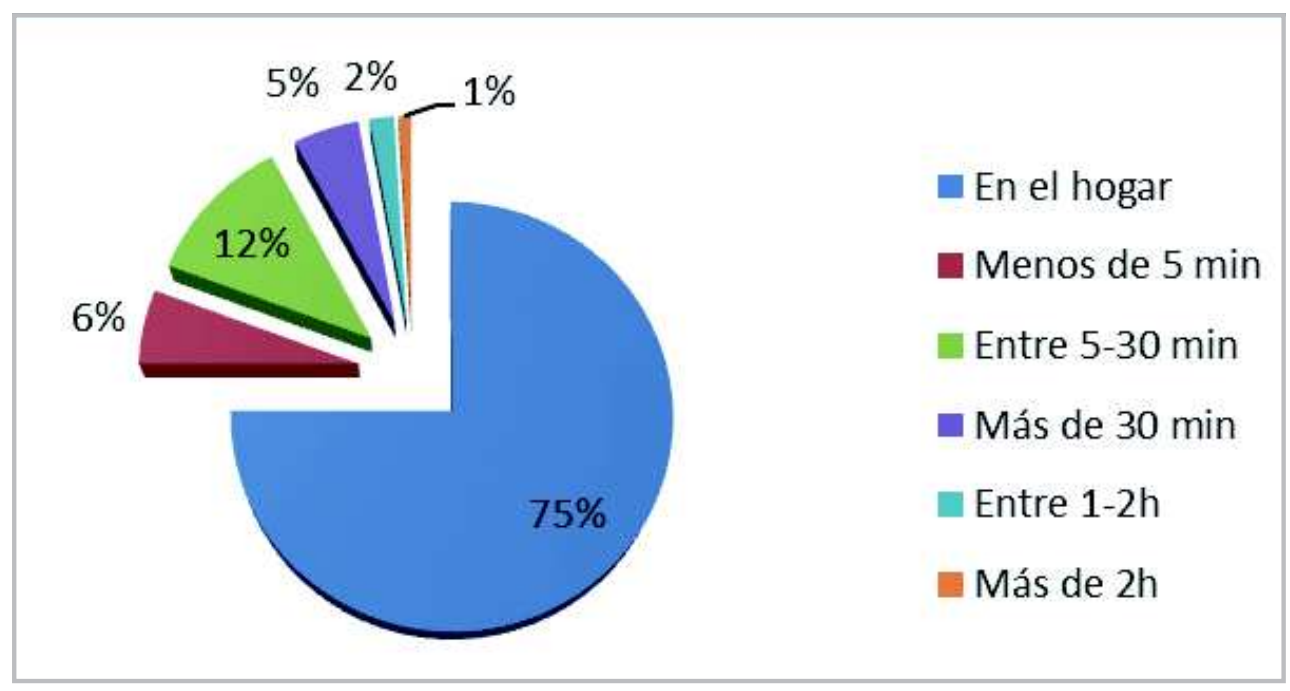

Fuente: elaboración propia.

En cuanto a quien se encarga de ir a por el agua, los resultados muestran que mayoritariamente son las mujeres adultas las que se encargan de esta tarea. Es de resaltar que también un porcentaje elevado de hombres, aunque en menor proporción que las mujeres, se encargan de ir a por agua. 
Gráfico 8. Recogida de agua por género

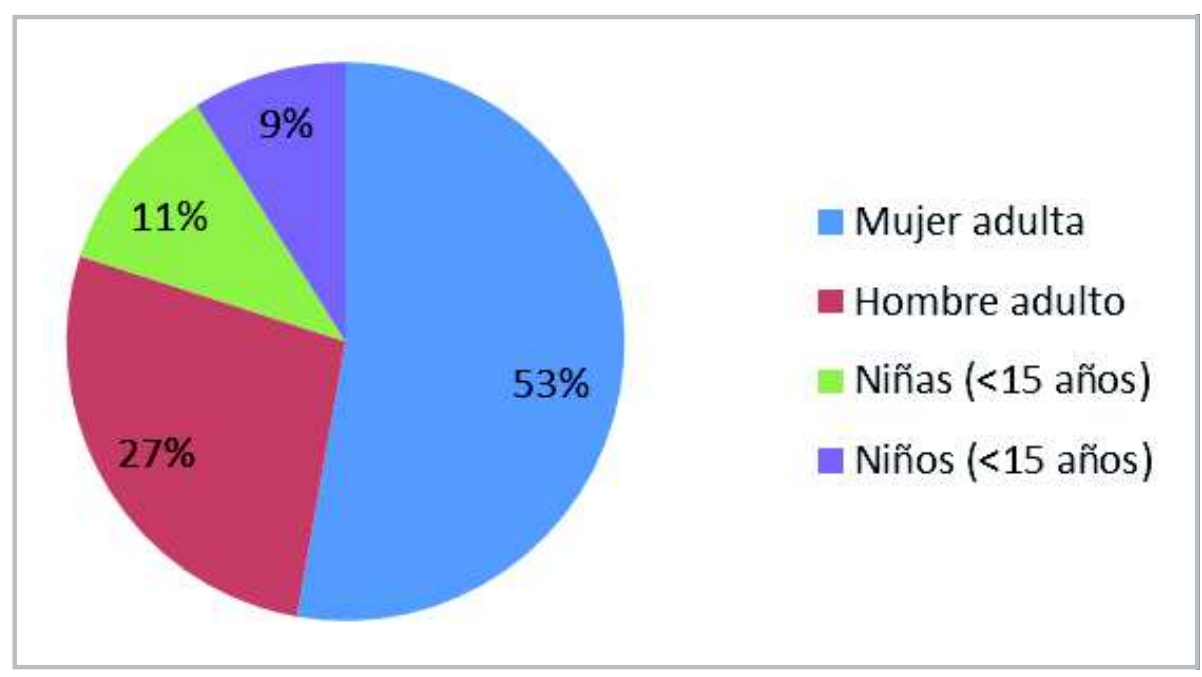

Fuente: elaboración propia.

Si analizamos estos resultados diferenciando el género de las personas que responden a la pregunta, se observa que la proporción anterior se modifica, ya que las mujeres consideran que son muchas más las mujeres que se encargan de la tarea de recoger el agua que los hombres. Así mismo, también se obtienen distintos resultados en cuanto al tiempo necesario para la recogida de agua dependiendo de si la persona que responde es hombre o mujer (ambos sin acceso al agua).

\section{I.3. Organización y gestión del agua}

Los CAPS predominan en la gestión y mantenimiento del servicio de agua potable, de tal manera que el $57 \%$ de los hogares encuestados reconoce una forma comunitaria organizada de gestión de agua. Además, alrededor de 2 de cada 10 hogares reconocen que las tareas de los CAPS van más allá del mantenimiento y la gestión del agua potable, destacando su papel en la organización de la comunidad y su liderazgo comunitario. Sin embargo, el papel de los CAPS hacia fuera de la comunidad (en el ámbito municipal y nacional) es muy poco visible. Esto quiere decir de alguna manera que su función política es en buena medida desapercibida.

\section{I.4. Calidad}

Las familias determinan la calidad del agua principalmente por su percepción, más que por comunicaciones o datos ofrecidos por las autoridades o los CAPS. 
Cabe destacar además que un 19\% contesta que no sabe si se realizan controles, lo que demuestra que hay un elevado desconocimiento por parte de las familias en cuanto a la calidad del agua que consumen.

En cuanto a los actores que deben monitorear y supervisar la calidad del agua, los CAPS consideran que principalmente es responsabilidad del MINSA, seguida de los CAPS y en menor medida de la alcaldía. Cabe destacar que los resultados obtenidos en las encuestas familiares en cuanto a los responsables de la calidad del agua son los mismos, aunque la comunidad considera que el MINSA tiene más responsabilidad que los CAPS.

Un número $32 \%$ de CAPS nunca clora y un $11 \%$, lo hace de forma puntual.

Sólo el $61 \%$ de las familias de las comunidades donde hay SAP se abastecen del mismo y de esas un $57 \%$ tienen un sistema periódico de control de calidad: $34.7 \%$ de las familias que habitan en comunidades donde hay un CAPS (les abastezcan o no), y esos CAPS tienen control de calidad el agua periódica.

En cuanto a las medidas de control y supervisión de la calidad de los SAP:

- Un número muy elevado de CAPS (42\%) manifiestan que se supervisa la calidad pero que el CAPS no participa.

- Un porcentaje importante de CAPS (22\%) consideran que la supervisión y monitorización la realizan los CAPS sin la ayuda de ningún otro actor.

Los resultados de la encuesta muestran que el 55\% de las familias no realizan ningún tratamiento para desinfectar el agua antes de beberla. Sin embargo, las familias que deciden realizar algún tratamiento al agua, suelen emplear métodos adecuados para ello, siendo lo métodos más utilizados la cloración del agua, el hervido y el uso de filtros cerámicos o de arena.

Un $58 \%$ de las familias no han recibido capacitación en materia de tratamiento de agua.

\subsubsection{Asequibilidad}

Se observa que la mayor parte de las familias (50\%) no pagan por tener acceso al agua y las familias que sí pagan por el agua, tienen unas tarifas muy dispares (100-50 córdobas/mes, que es equivalente a $3.78 \$-1.89 \$$ ) 
La mayoría de las familias que pagan una tarifa por el agua considera que la tarifa es justa. Casi un tercio de las familias consideran que es barata y sólo un $20 \%$ que es muy cara. Sin embargo, tanto las familias que consideran que la tarifa es muy cara, como las que la consideran justa, han tenido que ajustar su presupuesto para poder pagar la tarifa del agua, en una partida tan básica como la alimentación, seguida de electricidad y gastos relacionados con las reparaciones del hogar.

Casi la mitad de los CAPS encuestados consideran que existen sectores en la comunidad con dificultades para pagar la tarifa. Quienes más dificultades tienen para poder pagar la tarifa son las familias sin recursos y las familias encabezadas por una mujer sola, seguido de la población anciana. Sin embargo hay que destacar que la mayoría de los CAPS no lleva a cabo ninguna medida cuando sectores particularmente vulnerables no pueden pagar la cuota.

Otro dato a resaltar de la encuesta de los CAPS es que pese a que la gran mayoría de CAPS indican que no se corta el agua a personas de la comunidad, y todos indican que antes de cortar el agua se intentan llegar a acuerdos, cuando ha llegado el caso y se le ha cortado a algún miembro de la comunidad, en la mitad de los casos no se le ha asegurado una cantidad de agua para beber.

\subsection{Derecho humano al saneamiento}

Cabe destacar también los sistemas de saneamiento y eliminación de basuras, respecto a la cual el $88 \%$ de los hogares encuestados señalan que disponen de letrina. Un $4 \%$ señalan tener inodoro, pero algunos de ellos afirman que el inodoro descarga directamente al río.

Los hogares que carecen de servicio higiénico se encuentran concentrados en la zona norte y los municipios de las regiones autónomas. Pese a haber un $37 \%$ de los hogares que han sido objetivo de algún tipo de acción o proyecto de mejora de letrinas y de que un $5 \%$ de hogares que disponen de letrina la comparten con otras familias, éstas señalan que ante la limitada cobertura de las políticas públicas y los proyectos de organismos no gubernamentales la mayoría de las familias son las que llevan a cabo las labores de mejora o reconstrucción de las letrinas. El segundo actor en este sentido sería la Alcaldía, seguida por el FISE. Sin embargo, las entrevistas con los CAPS se puede desprender la casi total ausencia de medidas de tratamiento de aguas negras.

Referente a la eliminación de basuras, los hogares eliminan la basura fundamentalmente mediante la quema y tirándola a predios baldíos, si bien es cierto que hay un $16 \%$ de hogares que entierran la basura. 


\subsection{Disponibilidad de saneamiento}

Se obtienen diferentes resultados de las encuestas a familias y encuestas a CAPS:

Un $79 \%$ de las familias disponen de instalaciones de saneamiento mejoradas. Sin embargo un $14 \%$ de las familias no tienen acceso a instalaciones mejoradas, ya que no sólo se considera saneamiento no mejorado a aquel que no garantiza las condiciones higiénicas que impidan el contacto de las personas con los excrementos humanos, sino que también se considera saneamiento no mejorado a aquel saneamiento mejorado que tienen que ser compartido por varias familias. En este sentido un $11 \%$ de las familias tienen que compartir las instalaciones de saneamiento entre varias familias y un 3\% de las familias emplean letrinas de pozo sin losa o plataforma (losa abierta). Especialmente relevante es que un $7 \%$ de las familias defecan al aire libre.

En la encuesta de familias, un $64 \%$ de las familias disponen de instalaciones mejoradas, un $28 \%$ de instalaciones no mejoradas (incluyendo las instalaciones compartidas) y un $8 \%$ de la comunidad defeca al aire libre.

\section{Gráfico 9. Disponibilidad de saneamiento}

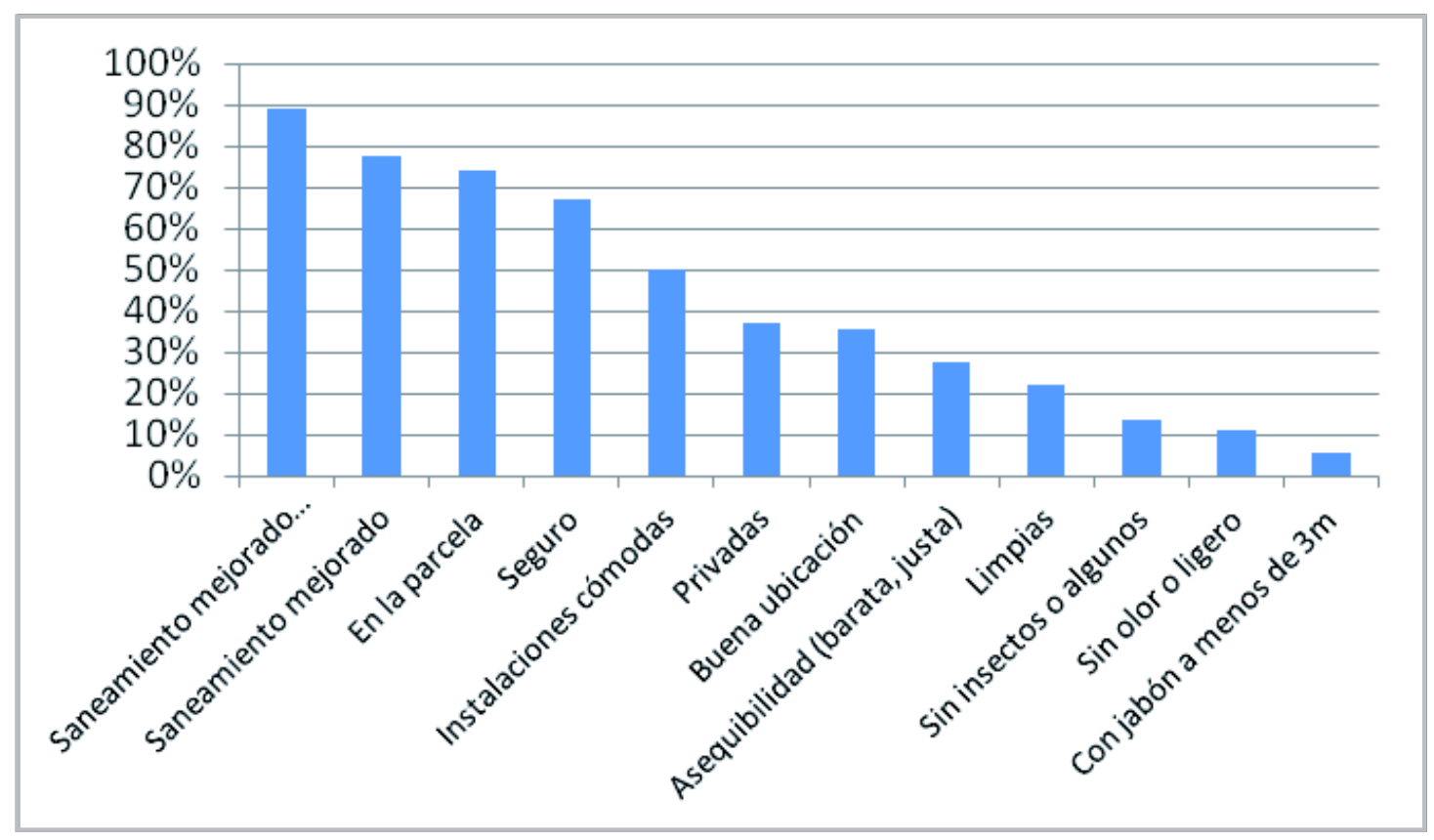

Fuente: elaboración propia. 
Un $15 \%$ de las familias comparten las instalaciones con otras familias y que además normalmente las familias disponen de una única letrina que pueda utilizarse.

Un alto porcentaje de la comunidad (41\%) considera que hay personas que defecan al aire libre en su comunidad de forma diaria. Por otro lado, muchas personas no saben qué responder a la pregunta (30\%), lo que demuestra que se trata de un tema tabú.

\subsubsection{Accesibilidad física al saneamiento}

Según los resultados obtenidos, casi la mitad de las familias encuestadas (43\%) no disponen de baño en sus hogares. Sin embargo, la mayoría de las instalaciones de saneamiento se encuentran en el interior de la parcela familiar.

En cuanto a la accesibilidad de las instalaciones en centros de salud y escuelas, destacar que, según los CAPS, en más de la mitad de las comunidades no hay hospitales ni centros de salud. Además, en los hospitales o centros de salud que existen en las comunidades, existe muy poca accesibilidad al saneamiento tal y como muestran los siguientes datos:

- Un 50\% no dispone de instalaciones de saneamiento

- Un 58\% no dispone de lavamanos en funcionamiento

- Un 39\% no promueven hábitos de higiene

En relación a las escuelas y centros educativos, cabe destacar que son mucho más numerosos en las comunidades que los hospitales o centros de salud ya que sólo un $15 \%$ de los CAPS responde que no existen en la comunidad. Los resultados en cuanto al acceso al saneamiento muestran que:

- Un $21 \%$ de las escuelas no disponen de instalaciones de saneamiento

- Un $62 \%$ de las escuelas no disponen de lavamanos en funcionamiento

- Un $16 \%$ de las escuelas no promueven hábitos de higiene

\subsubsection{Calidad del saneamiento}

Un 14\% familias considera que no están limpias, y es un $27 \%$ según los encuestadores.

En cuanto a la higiene personal se observa que un $43 \%$ de las familias no disponen de baños (duchas). Además, no existe ningún tipo de instalación para lavarse las 
manos a menos de $3 \mathrm{~m}$ de la letrina y más de la mitad de los encuestadores reportan que no existe jabón para lavarse las manos en las instalaciones de saneamiento. Si además se tiene en cuenta que el $7 \%$ de la población no usa las letrinas porque defeca al aire libre, se observa que sólo un 35\% de las familias tendría acceso a jabón para el lavado de manos en las instalaciones de saneamiento.

Como indicadores de la promoción de la higiene, según se indica en la metodología FECSA, se han medido los siguientes indicadores:

Prácticas higiénicas en familias con niños menores de 3 años: La mayoría de las familias depositan las heces de los niños en la letrina/inodoro o el niño defeca directamente en la letrina. Sin embargo casi un tercio de las familias las tiran al patio o a la basura o las entierran.

Almacenamiento de agua en los hogares: El estudio muestra que la mayoría de las familias emplean recipientes cerrados para almacenar el agua para beber. El $10 \%$ restante no almacena el agua o no lo hace correctamente.

\subsubsection{Asequibilidad del saneamiento}

Un $41 \%$ de las familias han podido construir los sistemas gracias a proyectos concedidos, frente a un $59 \%$ que los han construido con medios propios. En este sentido, las familias perciben justa a sus posibilidades su contribución en la construcción de las instalaciones de saneamiento. Todas las familias que defecan al aire libre están en los dos quintiles de mayor pobreza que la media.

\subsubsection{Aceptabilidad cultural del saneamiento}

Un $15 \%$ de las familias consideran que las letrinas no tienen privacidad. Además, a un $11 \%$ de familias no les gusta la ubicación de la letrina o inodoro y un $26 \%$ de las familias considera que las letrinas que existen en su comunidad no son cómodas, lo que repercute en que las usen menos. Son más las mujeres que consideran que las letrinas no tienen privacidad y les gusta menos la ubicación de las letrinas que a los hombres.

En cuanto a la adaptabilidad cultural de las instalaciones en centros de salud y escuelas, destacar que un $62 \%$ de los hospitales o centros de salud y un $46 \%$ de las escuelas, no disponen de servicios separados por sexos lo que puede incidir también en el derecho a la educación de las niñas a partir de los 10 años. 


\section{Discusión y conclusiones}

La conclusión más clara de nuestro estudio es el incumplimiento preocupante de las obligaciones del Estado en lo referente al derecho al agua y al saneamiento de gran cantidad de población rural (casi la mitad). De hecho, si se utilizan los datos de cobertura del Joint Monitoring Programme, la población que sí tiene cobertura de agua es más de un $80 \%$. Sin embargo, si se añaden todos los requisitos que implica el derecho al agua, tal y como se muestra en el gráfico a continuación (continuidad, suficiente para todos los usos, accesible físicamente, seguridad, etc), puede observarse que los porcentajes disminuyen de forma muy importante.

\section{Gráfico 10. Derecho al agua}

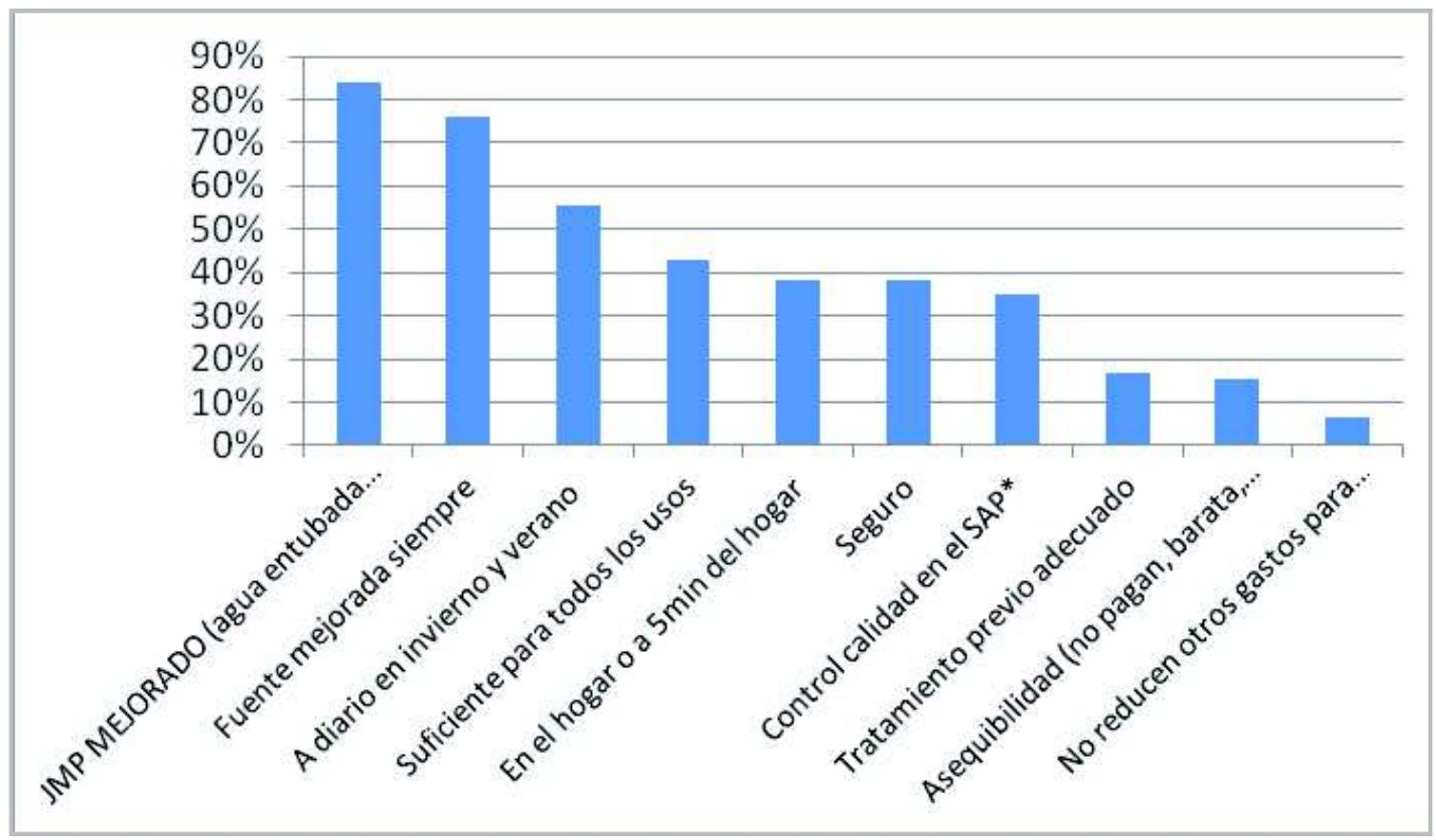

Fuente: elaboración propia.

Esto conlleva problemas para la población nicaragüense: Aumenta la carga laboral de las mujeres, creando importantes niveles de desigualdad. Además, la contaminación del agua por el deterioro ambiental y las modificaciones climatológicas provocan cerca del $80 \%$ de los problemas de salud que motivan consultas en el sistema público. $Y$ es que, aunque hay fuentes diversas, muchas veces el agua también está contaminada por aguas residuales. 
En cuanto al saneamiento, los resultados de la encuesta de familias arrojan los siguientes resultados: un $64 \%$ de las familias disponen de instalaciones mejoradas, un $28 \%$ de instalaciones no mejoradas (incluyendo las instalaciones compartidas) y un $8 \%$ de la comunidad defeca al aire libre.

En cuanto a las categorías transversales, las conclusiones principales son las siguientes:

- Participación: Entre el $30 \%$ y el $40 \%$ de las comunidades no tienen una participación significativa en torno al tema del agua. En cuanto al saneamiento un $27 \%$ de las familias no toman decisiones al respecto.

- Rendición de cuentas: Se da una ausencia de libros contables, asambleas de rendición y cuentas bancarias.

- No discriminación : Los factores de discriminación de facto son la etnia, región de residencia, sexo, nivel económico, número de años en asentamiento.

- Igualdad de género: Existen diferencias en la participación en la toma de decisiones, percepción de seguridad, privacidad en saneamiento y en cantidad suficiente de agua para todos los usos, además de en la percepción del tiempo de recogida de agua.

- Sostenibilidad: A pesar de los esfuerzos, los CAPS no garantizan la sostenibilidad económica, social y ambiental de los sistemas rurales.

Dado que la Observación General 15, en sup. $44^{9}$ establece ejemplos de violaciones al derecho humano al agua y al saneamiento, los hallazgos de nuestra investigación demuestran que el Estado de Nicaragua tiene una gran tarea pendiente y está incurriendo en vulneraciones del derecho humano al agua potable y al saneamiento.

9 "Aunque no es posible confeccionar por adelantado una lista completa de las violaciones, a partir de la labor del Comité se puede individualizar una serie de ejemplos típicos que ilustran los niveles de obligación: ii) no regular y controlar eficazmente los servicios de suministro de agua; iii) no proteger los sistemas de distribución de agua (por ejemplo, las redes de canalización y los pozos) de la injerencia indebida, el daño y la destrucción; c) Las violaciones de la obligación de cumplir se producen cuando los Estados Partes no adoptan todas las medidas necesarias para garantizar el disfrute del derecho al agua. Los siguientes son algunos ejemplos ii) asignar fondos insuficientes 0 asignarlos en forma incorrecta, con el resultado de menoscabar el disfrute del derecho al agua por personas o grupos, especialmente los vulnerables o marginados". 


\section{Referencias bibliográficas}

Albuquerque, C. y Roaf. V. (2011) Derechos hacia el final. Buenas prácticas en la realización de los derechos de agua y saneamiento. AECID, Ongawa, 2011

Alto Comisionado de las Naciones Unidas para los Derechos Humanos, OHCHR, UN-HABITAT y OMS, The Right to Water, Fact Sheet 35.

Barlow, M. (2013) Our right to water. A People's Guide to Implementing the United Nations' Recognition of the Right to Water and Sanitation. Ottawa, The Council of Canadians.

Barlow, M. (2009) El Convenio Azul. La crisis global del agua y la batalla futura por el derecho al agua. Heinrich Böll Stiftung, Chile Sustentable.

Klemm, E., Grant, P., Meehan, P. and Anton, C. (2012) BDP Occasional Paper . Respect, Protect and Fulfil- The Right to Water and its impact on water service delivery arrangements. (DRAFT)

COHRE (2004) Legal Resources for the Right to Water: International and National Standards. Geneva, COHRE (Centre on Housing Rights and Evictions).

COHRE (2007) Manual sobre el derecho al agua y al saneamiento. COHRE, AAAS, UN-HABITAT, SDC.

COHRE (2008) Operational Guide for implementing Rights Based Approaches to Water and Sanitation Programming. COHRE (Centre for Housing Rights and Evictions).

Censos nacionales de Nicaragua. Instituto Nacional de Información de Desarrollo. (http://www.inide.gob.ni/)

Constitución de la República de Nicaragua (2007). (http://www.ineter.gob.ni/Constitucion\%20Politica\%20de\%20Nicargua.pdf)

Convención Americana sobre Derechos Humanos, "Pacto de San José", Costa Rica (1969). (http://www.oas.org/dil/esp/tratados_B-32_Convencion_Americana_sobre_Derechos_Humanos.htm)

CONVENCIÓn de los DereCHOS del NiÑo (1989). (hHtp://www.unicef.org/panama/ spanish/convencion(3).pdf ) 


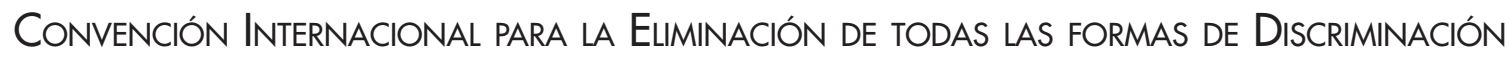
RACIAL (1966). (http://www.tc.gob.pe/tratados/uni_ddhh/instru_alca_especifi_uni/ instru_dere_civ/ident_etni_cult/form_elim_racial.pdf)

Declaración Americana de los Derechos y Deberes del Hombre (1948). (hHtps://www. oas.org/dil/esp/Declaraci\%C3\%B3n_Americana_de_los_Derechos_y_Deberes_del_Hombre_1948.pdf)

Declaración Universal de los Derechos Humanos (1948). (hitp://www.un.org/es/ documents/udhr/)

FERNÁNDEZ Aller, C. (coord.). Marco teórico para la puesta en práctica del enfoque de derechos humanos. (http://www.reduniversitaria.es/ficheros/Marco\%20 teórico\%20LIBROS.pdf)

Informe sobre DesarRollo Humano (2006) Más allá de la escasez: poder, pobreza y la crisis mundial del agua. (http://hdr.undp.org/sites/default/files/hdr_2006_ es_completo.pdf)

Ley 620 - Ley General de Aguas Nacionales, 2007. (http://www.asdenic.org/ wp-content/uploads/2012/07/ley_agua_620.pdf)

Ley de Comités de Agua Potable y Saneamiento CAPS, Ley 722. (http://www. asamblea.gob.ni/odm/OBJETIVO\%207/1.LEY/2010.G111.LEY\%20722.PDF)

Ley General de Salud, 2002. (http://www.ilo.org/dyn/travail/docs/2199/LEY\%20 No.\%20423\%20del\%2014\%20de\%20Marzo\%20del\%202002.pdf)

Luis Romero, E.; Fernández Aller, C. y Guzmán Acha, C. (2013) Derecho Humano al Agua y al Saneamiento. Guía para la incorporación del enfoque basado en derechos humanos (EBDH). UPM, ONGAWA. (http://www.ongawa.org/wp-content/ uploads/2013/09/DHAguaysaneamiento.pdf)

Pacto Internacional de Derechos Sociales, Económicos y Culturales PIDESC (1966). (http://www.tc.gob.pe/tratados/uni_ddhh/instru_alca_gene2/pidesc.pdf)

Protocolo de Reformas a la Carta de la Organización de los Estados Americanos. Protocolo de Buenos Aires (1967). (http://www.oas.org/dil/esp/tratados_B-31_ Protocolo_de_Buenos_Aires.htm) 